\title{
Desafío Normativo: Protección Internacional de Refugiados y Apátridas en Ecuador
}

\author{
Editado por/Edited by: Víctor Cabezas \\ Recibido/Received: 26/01/2014. Aceptado/Accepted: 15/05/2014 \\ Publicado en línea/Published on Web: 10/09/2014
}

\begin{abstract}
Johanna Roldán
Abogada, Universidad Católica del Ecuador; Diploma Superior en Derechos Humanos y Democracia en América Latina, Universidad Andina Simon Bolivar; Máster en Derecho, Duke University. Funcionaria del ACNUR en Ecuador desde el 2006. Este artículo no representa la posición institucional del ACNUR. Correo electrónico: roldan@unhcr.org
\end{abstract}

\section{Resumen}

Este artículo pretende identificar los principales desafíos que enfrenta el Ecuador en relación a la protección internacional de personas refugiadas y apátridas. Inicialmente se establece el contexto normativo ecuatoriano, en el que se elimina la clasificación tradicional de derechos para enfatizar la igual jerarquía de derechos constitucionales. A continuación se hace referencia a varias directrices para fortalecer la protección de refugiados. Entre ellas se considera garantizar derechos fundamentales de solicitantes de estatus de refugiados y refugiados reconocidos, a través de integración local y de mecanismos procedimentales más eficientes. Asimismo, se enfatiza la necesidad de designar una autoridad pertinente para definir un procedimiento de determinación del estatuto de apátrida en Ecuador. Finalmente, se realiza un comentario sobre la determinación de un estatuto humanitario como una forma de protección complementaria para personas en necesidad de protección internacional.

Palabras clave: refugiado, apátrida, protección internacional, asilo, movilidad humana.

\section{Abstract}

This article intends to identify the main challenges Ecuador faces in regards to the international protection of refugees and stateless people. Firstly, the Ecuadorian normative context is established and described, in which the traditional classification of rights is eliminated in order to emphasize the equivalent hierarchy of constitutional rights. Furthermore, there is reference to guidelines to strengthen the protection of refugees. Among them is recognized the necessity of guaranteeing the fundamental rights of asylum seekers and recognized refugees, through local integration and more efficient procedural mechanisms. As well, the article recognizes the necessity of appointing an authority to define the best assessment procedure for statelessness in Ecuador. Finally, a commentary regarding the determination of a humanitarian statute as a means of supporting persons in need of international protection (PINPs) is presented.

Palabras clave: refugee, stateless, international protection, asylum, human mobility.

A partir de la promulgación de la Constitución en octubre de 2008, el Ecuador atraviesa una interesante etapa de adecuación de su ordenamiento jurídico a los estándares establecidos en la nueva Carta Magna. Así, por ejemplo, en lo referente al reconocimiento, protección y exigibilidad de derechos humanos, la Constitución ha sido reconocida por su carácter progresista y garantista. No obstante, ese carácter implica un gran desafío en la construcción y adopción de las reformas normativas pertinentes, que reflejen el espíritu garantista originado en Montecristi.

Adicionalmente, la Constitución de 2008 elimina la clasificación tradicional de derechos, con el propósito de enfatizar el carácter complementario y la igual jerarquía de todos los derechos constitucionales (Trujillo \& Ávila Santamaría, 2008). Así lo señala la Constitución en su artículo 3.1, estableciendo como un deber primordial del Estado el "garantizar sin discriminación alguna el efectivo goce de los derechos establecidos en la Constitución y en los instrumentos internacionales [...]". Esta referencia a los derechos reconocidos en los instrumentos internacionales de derechos humanos se repite en varios artículos de la Constitución (ver, en particular, los artículos 10, 11.3, y 172).

El efecto de esta reiteración es la incorporación de los derechos contenidos en dichos instrumentos en la Constitución, formando así parte del denominado bloque constitucional. La noción 'bloque de constitucionalidad' -originado en el constitucionalismo europeo- es una herramienta que permite establecer "qué elementos ajenos a la articulación de la Constitución formal se incorporan al acervo constitucional de derechos fundamentales" (Nash Rojas, 2012: p. 43).

Dentro de esta institución (bloque de constitucionalidad) no existe un sistema jerárquico, sino que cada uno de los elementos es considerado en un plano de igualdad, lo que implica la necesidad de conciliar las distintas disposiciones y, por tanto, obliga a avanzar en la coherencia del sistema (Nash Rojas, 2012: p. 44). En otras palabras, el marco legal que actualmen- 
te otorga la Constitución ecuatoriana está conformado no sólo por los derechos formalmente allí establecidos, sino también por los derechos que se encuentran consagrados en los tratados internacionales de derechos humanos vigentes en el Ecuador.

El tratadista Luigi Ferrajoli ha denominado este modelo como "democracia constitucional", un sistema jurídico-político en el que la toma de decisiones y la voluntad de la mayoría está limitada por los derechos humanos establecidos en el Derecho Internacional y en la Constitución. Es más, las leyes y las políticas públicas no podrían violar los derechos humanos y, por tanto, también están sometidas a la Constitución (Grijalva Jiménez, 2011).

Respecto al tema que nos acoge, la Constitución del Ecuador reconoce los derechos de asilo y refugio (Art. 41), y establece que deben ser regulados mediante ley orgánica (Art. 133.2). La regulación de los derechos de asilo y refugio debe plasmarse en una ley orgánica, no solamente por mandato constitucional, sino también convencional, dado que la Convención Americana sobre Derechos Humanos, en su artículo 2, así lo establece. No obstante, el procedimiento de asilo en el Ecuador está normado vía reglamento.

El 30 de mayo de 2012 se expidió el Decreto Ejecutivo 1182, como respuesta del Estado ecuatoriano frente a las aparentes deficiencias en el procedimiento de asilo, que estaba anteriormente establecido en el Decreto Ejecutivo 3301 de 1992. El proceso de adopción del nuevo Decreto fue paralelo a la preocupación de distintas esferas del Estado sobre un incremento de solicitudes abusivas e infundadas y la percepción de que en el pasado la determinación de la condición de refugiado había sido poco rigurosa.

Actualmente, en el país se ha renovado el debate en torno a la necesidad de promulgar una ley integral sobre movilidad humana. A fines del 2013, se conformó el Grupo Parlamentario por los derechos de las personas en situación de movilidad humana, un espacio al interior de la Asamblea Nacional donde se ha discutido sobre la necesidad y los contenidos de esta ley. Por otro lado, la Defensoría del Pueblo presentó un anteproyecto de ley, el cual fue socializado en distintas provincias del país y puesto a consideración del Viceministerio de Movilidad Humana dentro de la Cancillería ecuatoriana, que - a propósito - fue creado en junio de 2013 para tomar las funciones de la anterior Secretaría Nacional del Migrante.

Dado el interés en el tema proveniente de varios sectores tanto del Ejecutivo, Legislativo y sociedad civil, sería muy beneficioso aunar esfuerzos y concertar un solo proyecto que garantice los derechos de las personas migrantes, refugiadas, apátridas y sus familias consagrados en la Constitución y en los diferentes convenios internacionales ratificados por el Ecuador.

El Alto Comisionado de las Naciones Unidas para los Refugiados (ACNUR) considera que ésta es una valiosa oportunidad para debatir y decidir sobre temas pendientes en materia de asilo, apatridia y formas complementarias de protección para personas que no reúnen los elementos para ser reconocidos como refugiadas pero que sí requieren protección internacional.

En cuanto a la protección de refugiados, sería importante insertar tanto los estándares internacionales como constitucionales relacionados a la materia, garantizar el respeto a los derechos fundamentales de los solicitantes de la condición de refugiado y de los refugiados reconocidos y coadyuvar a su integración local como principal solución duradera. En particular, el ACNUR subraya la necesidad de incorporar reformas que viabilicen el goce y ejercicio efectivo de los derechos de la población refugiada, v.gr., la identificación de la población refugiada con un documento de reconocimiento general y que no produzca exclusión.

Por otro lado, es vital el garantizar el acceso a los servicios de educación, salud, vivienda, seguridad social, financieros, etc. y el pleno ejercicio del derecho al trabajo, es decir, eliminar los impedimentos legales y reducir los obstáculos administrativos para facilitar la integración de los refugiados y posibilitar el desempeño de las actividades básicas de todo ciudadano, siguiendo lo establecido en la propia Constitución: “Art. 9.- Las personas extranjeras que se encuentren en el territorio ecuatoriano tendrán los mismos derechos y deberes que las ecuatorianas, de acuerdo con la Constitución."

Igualmente importante es el mejorar y fortalecer los mecanismos procedimentales vigentes y la institucionalidad para contar con un sistema para la determinación de la condición de refugiado más ágil y eficiente, tanto en la primera fase de elegibilidad a como en la etapa de apelación en sede administrativa, respetando los principios del debido proceso y difundiendo el respeto y garantía de los mismos a todos los niveles de autoridad involucrados. Respecto a las garantías dentro de los procedimientos para determinar la condición de refugiado, se podría remitir a las directrices que el ACNUR ha producido, así como también a la reciente sentencia de la Corte Interamericana de Derechos Humanos en el caso Familia Pacheco Tineo vs. Estado Plurinacional de Bolivia (Caso Familia Pacheco Tineo v. Estado Plurinacional de Bolivia, 2013).

De otra parte, la asimilación de la condición de refugiado como un estatuto meramente migratorio debe ser superada, en el sentido de que ser refugiado no equivale a ser un migrante $y$, por lo tanto, se debería abrir la posibilidad para que un refugiado dentro de su proceso de integración pueda adquirir otro tipo de visa sin tener que renunciar a su condición de refugiado, condición que le brinda protección internacional y le protege contra la devolución, piedra angular del Derecho Internacional de Refugiados.

Cabe mencionar a breves rasgos lo que significa la protección internacional. Los diferentes instrumentos internacionales y regionales de derechos humanos regulan la protección internacional como un mecanismo substituto de la protección nacional, por lo que se espera que dicho mecanismo sea temporal, provisional, hasta que el refugiado o la persona que lo requiera pueda volver a beneficiarse de la protección de su Estado, bien porque regrese voluntariamente a su país de origen (repatriación), o porque adopte otra nacionalidad. De aquí que no debe considerarse a un refugiado automáticamente como un migrante.

En relación a la apatridia, y luego de la reciente adhesión del Ecuador a la Convención para Reducir los Casos de Apatridia de 1961, y siendo además un Estado Parte de la Convención sobre el Estatuto de los Apátridas de 1954, es fundamental designar una autoridad competente y definir un procedimiento específico para la determinación del estatuto de apátrida. Si bien una persona a la que ningún Estado considera destinatario de la aplicación de su legislación podría reunir los elementos para ser 
reconocido como refugiado (según la definición de la Convención de 1951 sobre el Estatuto de los Refugiados), existen personas apátridas que no tendrían esa condición al no presentar un fundado temor de persecución, pero que aun así requieren de protección internacional. Es en esta situación donde existe un vacío legal que podría ser subsanado dentro de la elaboración de una ley de movilidad humana, por ejemplo. En la región, la determinación del estatuto de apátrida ha sido incorporada en las legislaciones de Costa Rica y Panamá.

Por último, quisiera referirme a la posibilidad de establecer la determinación de un estatuto humanitario como una forma de protección complementaria en favor de aquellas personas que requieren protección internacional pero que no estarían amparadas por instrumentos internacionales o regionales de protección a refugiados. Algunas obligaciones de derechos humanos, particularmente la protección del derecho a la vida y la prohibición absoluta de tortura, suponen la prohibición de la devolución al lugar donde la vida, libertad, integridad y seguridad de la persona estén amenazadas. La no devolución (non refoulement, en inglés) es considerada un componente fundamental del derecho consuetudinario internacional.

En efecto, el Art. 3 de la Convención contra la Tortura y otros Tratos o Penas Crueles, Inhumanos o Degradantes de 1984 (CAT) y el Art. 22.7 de la Convención Americana de Derechos Humanos de 1969, ratificadas por el Ecuador, se refieren en forma explícita a la obligación de no devolver a una persona a un país en el cual corra peligro de ser sometida a tortura. Es más, el Ecuador ha ratificado también el Protocolo a la Convención Americana sobre Derechos Humanos, relativo a la Abolición de la Pena de Muerte, lo que implica no solamente que no aplicará esta sanción en su territorio, sino que además velará porque ninguno de los habitantes bajo su jurisdicción se exponga al riesgo de ser sometido a la pena de muerte.

No obstante, estos instrumentos no brindan a las personas que requieren protección un estatuto claramente definido y reconocido internacionalmente, o una condición legal específica de residencia, ni documentos de viaje o de identificación como tampoco existen disposiciones específicas sobre una eventual integración y naturalización, aun cuando algunas de estas deficiencias hayan sido contempladas por la legislación nacional.

Precisamente, algunos países de asilo tienen mecanismos administrativos o legislativos establecidos para regularizar la permanencia de personas que no son reconocidas formalmente como refugiadas, pero para las que el retorno no es posible ni recomendable por razones varias, como por ejemplo condición médica severa, relaciones familiares, o riesgo de tortura, entre otras. Es una forma positiva de responder de manera pragmática a determinadas necesidades de protección internacional. Según principios universales de derechos humanos, las personas a las que se autorice la permanencia en un país por necesidades de protección, deben gozar de un estatuto que les permita llevar una vida digna. Teniendo en cuenta las graves circunstancias sufridas por estas personas, es necesario que cuenten con un grado de seguridad y estabilidad adecuado.

Desde el punto de vista del ACNUR, no es suficiente la mera suspensión de la deportación. Los beneficiarios de las formas complementarias de protección deberían disfrutar de un estatu- to legalmente reconocido, con derechos y obligaciones definidos y deberían ser dotados de documentos que certifiquen dicho estatuto. Este estatuto debería ser prorrogado durante el tiempo necesario para permitir a los beneficiarios recuperar la normalidad en sus vidas o por el tiempo que se requiera protección internacional (Alto Comisionado de las Naciones Unidas para los Refugiados, 2005).

En fin, el propósito de este artículo ha sido abrir un espacio para la reflexión en torno a la necesidad y oportunidad de construir una ley de movilidad humana que incluya la regulación de los derechos de asilo y refugio, la protección de las personas apátridas y otras formas complementarias de brindar protección internacional.

\section{Referencias}

Alto Comisionado de las Naciones Unidas para los Refugiados (ACNUR). (2005). Protección Internacional mediante formas complementarias de protección. EC/55/SC/CRP. Recuperado de ACNUR: http://www.acnur.org/biblioteca/ pdf/4192.pdf

Caso Familia Pacheco Tineo v. Estado Plurinacional de Bolivia (Corte Interamericana de Derechos Humanos 25 de Noviembre de 2013).

Constitución de la República del Ecuador (2008), Artículo 441.

Grijalva Jiménez, A. (2011). Constitucionalismo en el Ecuador. Quito: Centro de Estudios y Difusión del Derecho Constitucional.

Nash Rojas, C. (2012). Derecho Internacional de los Derechos Humanos en Chile. Recepción y aplicación en el ámbito interno. Recuperado de Universidad de Chile: http://www.cdh. uchile.cl/media/publicaciones/pdf/91.pdf

Roldán, J. (2011). El Registro Ampliado de Refugiados en la Frontera Norte del Ecuador: Un proyecto pionero en la protección internacional de refugiados en la región. En Alto Comisionado de las Naciones Unidas para los Refugiados. (2011). La protección internacional de refugiados en las Américas. Quito.

Trujillo, J. C., \& Ávila Santamaría, R. (2008). Los derechos en el proyecto de Constitución. Revista La Tendencia, 68-85. 